\title{
Pengaruh Penggunaan Kursi Kerja Ergonomis Terhadap Penurunan Keluhan Nyeri dan Stress Kerja pada Pekerja Perusahaan Lampu X di Yogyakarta
}

\author{
Setyawati L. ${ }^{1}$, Bungakaraeng ${ }^{2}$ \\ 1,2) Universitas Gadjah Mada Yogyakarta \\ Email: lientjemaurits@yahoo.com
}

\begin{abstract}
ABSTRAK
Ergonomi perlu diterapkan diberbagai tempat termasuk di sekolah, ditempat kerja maupun ditempat lain agar dapat diperoleh kenyamanan dan peningkata produktivitas. Melakukan pekerjaan dengan menggunakan alat kerja dan stasiun kerja yang tidak ergonomis dapat menimbulkan gangguan musculoskeletal dengan adanya rasa nyeri dan pegal serta adanya ketegangan, mudah gelisah, bosan, dan lain-lain keluhan stress kerja yang berdampak terhadap terjadinya kecelakaan kerja dan penyakit akibat kerja. Tujuan penelitian ini adalah untuk mengetahui adanya penurunan keluhan nyeri dan stress kerja yang dialami pekerja di perusahaan lampu X di Yogyakarta.

Jenis penelitian ini adalah penelitian eksperimental dengan pre test, post test one group design, yang dilakukan pada 21 pekerja sebagai subyek penelitian yang berlangsung pada bulan Juli 2004 di perusahaan lampu X di Yogyakarta. Variabel penelitian terdiri atas variabel bebas yaitu kursi kerja ergonomis sedang variabel terikat adalah keluhan nyeri dan angka stress kerja. Analisis data menggunakan uji-t amatan ulangan dengan program computer SPS 2000.

Hasil uji statistic menunjukkan penurunan keluhan nyeri yang sangat significan antara kelompok pre test (mean = $43.14)$ dan post test $($ mean $=28.14)$ dengan $t=11.771(p=0.000)$. Hasil uji-t amatan ulangan selanjutnya menunjukkan penurunan stress kerja yang sangat significant antara kelompok pre test (mean $=52.238)$ dan post test $($ mean $=43.762)$ dengan nilai $t=7.385(p=0.000)$.
\end{abstract}

Kata kunci: Ergonomi, nyeri, stress kerja, kursi kerja.

\begin{abstract}
Ergonomics should be implemented in many places i.e. school, work place, and others to let the comfortness and increasing the work productivity. Conducting work with non-ergonomics tools and work station could cause musculoskeletal disorders such as painful / stiff, and work stress reaction like nervous, worried, not concentrate, and bored feeling, having impact for the accidents and illness of work. The aim of the research was to know the work stress and painful complaint reduction from the lamp factory PT. X after using ergonomic work chair.

The research was an experimental research with the pre-test post-test one group design conducted the research subject of 21 employees July 2004 in the lamp factory PT. X Yogyakarta. Variables used contained of independent variable, work chair, and dependent variables, work stress and painful complaint. The data analysis used the correlated t-test with the computer program of SPS 2000 (Series of Statistic Programmed-2000).

The result of the correlated t-test showed the really significant painful complaint reduction between the pre-test group $($ mean $=43.14)$ and post test group $($ mean $=24.14)$ with $t=11.771(p=0.000)$. The other result of the correlated t-test showed the very significant work stress reduction between the pre-test group (mean $=52.238)$ and post test group $($ mean $=$ 43.762) with the value of $t=7.385(p=0.000)$.
\end{abstract}

Keywords: Ergonomics, pain, work stress, work chair

\section{Pendahuluan}

Ergonomi perlu diterapkan diberbagai tempat termasuk di sekolah, ditempat kerja maupun ditempat lain agar dapat diperoleh kenyamanan dan peningkata produktivitas. Melakukan pekerjaan dengan menggunakan alat kerja dan stasiun kerja yang tidak ergonomis dapat menimbulkan gangguan musculoskeletal dengan adanya rasa nyeri dan pegal serta adanya ketegangan, mudah gelisah, bosan, dan lain-lain keluhan stress kerja yang berdampak terhadap terjadinya kecelakaan kerja dan penyakit akibat kerja disamping penurunan produktivitas kerja. Grandjean (1993) mengutarakan bahwa peralatan kerja yang ergonomis merupakan salah satu hal yang dapat memengaruhi kenyamanan kerja. Jika kursi kerja tidak ergonomis selain dapat menimbulkan keluhan nyeri dapat pula menjadi salah satu penyebab timbulnya stress (stressor) bagi pekerja. Sebaliknya kursi kerja yang ergonomis dapat meningkatkan rasa nyaman, penurunan rasa neyeri, penurunan stress kerja yang dialami pekerja yang menggunakan kursi tersebut. Setyawati (2000) meneliti pekerja non formal yaitu pembatik tulis di Yogyakarta, mengungkapkan bahwa kelelahan yang dialami pekerja pembatik tulis antara lain karena penggunaan tempat duduk yang tidak ergonomis. 
PT. X merupakan perusahaan lampu di Yogyakarta yang didalam pengamatan peneliti beberapa pekerja yang memakai peralatan tidak ergonomis mengeluh nyeri dan datang ke poliklinik perusahaan. Adakah pengaruh penggunaan kursi kerja yang ergonomis terhadap keluhan nyeri yang dialami pekerja dan stress yang dialami pekerja yang menggunakan kursi kerja tidak ergonomis tersebut.

\section{MetodePenelitian}

Penelitian ini adalah penelitian jenis eksperimental dengan pre test dan post test one group design. Observasi dilakukan dalam dua tahap yaitu sebelum perlakuan dan sesudah perlakuan. Perlakuan yang dimaksud adalah penggunaan kursi kerja baru yang ergonomis. Kursi kerja ergonomis adalah kursi kerja hasil rancangan berdasar kaidah ergonomi yang disiapkan oleh tim ergonomi di perusahaan yang terdapat di bagian $\mathrm{K} 3$ dan pelayanan kesehatan kerja. Pada rancangan penelitian eksperimental ulangan diperoleh dua kelompok yaitu kelompok sebelum perlakuan dan kelompok sesudah perlakuan. Kelompok sebelum perlakukan yaitu kelompok pekerja yang masih menggunakan kursi lama sedang kelompok kedua yaitu kelompok pekerja yang telah menggunakan kursi kerja baru yang ergonomis.

Perubahan yang terjadi dari efek perlakuan penggunaan kursi ergonomis baik terhadap keluhan nyeri maupun stress kerja yang dialami pekerja tidak sepenuhnya dipengaruhi oleh perlakuan karena tidak semua variabel luar yang turut berpengaruh dikendalikan (Pratiknya, 1993).

\section{Lokasi Penelitian}

Penelitian ini dilakukan di perusahaan lampu PT. X di Yogyakarta

\section{Populasi dan Sample Penelitian}

Populasi dalam penelitian ini adalah pekerja bagian pijar sebanyak 318 orang yang memenuhi criteria inklusi yang terdiri atas usia produktif 18 - 50 tahun, masa kerja lebih dari satu tahun, tidak menderita suatu penyakit yang ada kaitannya dengan otot. Sample ditentukan dengan cara purposive random sampling yaitu berdasarkan pertimbangan tertentu, menggunakan kursi baru yang telah dirancang secara ergonomis berjumlah 21 orang dan seluruh sample perempuan.

\section{Variabel Penelitian}

a. Variabel bebas adalah kursi kerja yang terdiri atas kursi kerja lama yang tidak ergonomis dan kursi kerja baru yang ergonomis.

b. Variabel terikat adalah keluhan nyeri dan stress kerja.

\section{Definisi Operasional}

a) Kursi kerja tidak ergonomis adalah kursi lama yang tidak memenuhi syarat ergonomis yang digunakan oleh pekerja di bagian pijar pada saat bekerja dan berskala nominal.

b) Kursi kerja ergonomis adalah kursi baru hasil rancangan secara ergonomis yang digunakan oleh pekerja bagian pijar saat bekerja dan skala nominal.

c) Nyeri adalah keluhan yang dialami pekerja di bagian pijar saat bekerja yang menggunakan kursi kerja tidak ergonomis selama pekerjaannya. Diukur dengan Nordic Body Map (Corlett, 1992), skala interval.

d) Stress kerja adalah beban fisik dan psikis yang dialami pekerja di bagian pijar yang pada saat bekerja dengan kursi tidak ergonomis. Keluhan tersebut diukur dengan angket stress kerja dan skala interval.

\section{Alat Penelitian}

A. Keluhan nyeri diukur dengan angket Nordic Body Map yang dimodifikasi. Pengukuran keluhan nyeri dibagi menjadi tiga bagian yaitu :

1. Keluhan nyeri pada leher, bahu dan punggung sebanyak enam pernyataan

2. Keluhan nyeri bagian lengan, tangan dan pergelangan tangan sebanyak enam pernyataan

3. Keluhan nyeri pada bagian paha, betis dan kaki sebanyak 8 butir pernyataan

B. Kursi kerja ergonomis yaitu kursi yang dirancang oleh tim K3 dan pelayanan kesehatan peusahaan, berdasar data antropometri pekerja, dengan pertimbangan stasiun kerja, jenis pekerjaan, alat yang digunakan pekerja tersebut.

C. Alat ukur stress kerja adalah angket stress kerja hasil adaptasi Grandjean (1993) dan Setyawati (1994).

\section{Hasil dan Pembahasan}

Di bagian pijar perusahaan lampu PT. X di Yogyakarta suhu lingkungan kerja menunjukkan suhu udara $30^{\circ}-37^{\circ} \mathrm{C}$, suhu basah $25^{\circ}-29^{\circ} \mathrm{C}$, kelembaban $54-65 \%$ sedang kebisingan 81 - $86 \mathrm{~dB}$. Umur subyek dalam penelitian ini : $30-49$ tahun dan yang terbanyak umur 40 - 44 tahun sebanyak $38 \%$ sedang masa kerja subyek 5 - 24 tahun dan tingkat pendidikan subyek $80.95 \%$ lulusan SLTA. 


\section{Hasil Pengukuran Keluhan Nyeri}

Secara keseluruhan jika dilihat dari setiap faktor maka skor tertinggi adalah keluhan nyeri di leher bagian belakang, bahu, dan punggung dengan mean pre test $=15.90$ dan mean post test $=7.71$ dengan gain skor $=-8.19$. Sedang faktor keluhan nyeri pada paha, betis, kaki dengan mean pree test $=15.52$ dan mean post test $=11.33$ dengan gain skor $=4.19$. Faktor keluhan nyeri pada lengan dan tangan dengan mean pre test $=11.71$ dan mean post test $=9.10$ dengan gain skor $=-2.62$.

\section{Hasil Pengukuran Stress Keja}

Mean variable stress kerja pada pre test $=52.24$ dan post test $=42.76$ dengan gain skor stress kerja $=-8.48$. Jika dilihat pada setiap faktor maka secara berurutan mulai dari gain skor tertinggi adalah faktor fisik dengan mean pre test $=19.24$ dan mean post test $=15.29$ dengan gain skor $=-3.95$. Faktor emosi dengan mean pre test $=16 \%$ dan mean post test $=13.48$ dengan gain skor $=-2.52$. Faktor perilaku dengan mean pre test $=17.00$ dan mean post test $=15.00$ dengan gain skor $=-2.00$.

\section{Analisis Hipotesis}

Uji-t amatan ulangan digunakan untuk menguji hipotesis pertama yaitu untuk mengetahui penurunan keluhan nyeri antara sebelum perlakuan dan sesudah perlakuan menggunakan kursi kerja ergonomis dan hipotesis kedua yaitu untuk mengetahui penurunan stress kerja antara sebelum perlakuan dengan stress kerja sesudah perlakuan menggunakan kursi kerja yang ergonomis. Hasil menunjukkan bahwa kelainan berupa keluhan nyeri yang dialami pekerja bagian pijar antara lain disebabkan oleh kursi kerja yang tidak ergonomis sehingga dengan pergantian kursi lama ke kursi baru yang ergonomis sangat efektif mengurangi keluhan nyeri pekerja. Hal ini sejalan dengan penelitian Purnawan (2000) pada pengrajin layanglayang di Sanur Bali dan hasil yang dilaporkan Puja (2000) pada penelitian pekerja pengrajin batok kelapa. Sikap kerja yang tidak alamiah pada umumnya disebabkan oleh tuntutan tugas alat kerja dan stasiun kerja yang tidak sesuai dengan kemampuan dan keterbatasan pekerja seperti diutarakan Grandjean (1993) dan Manuaba (2000).

OSHA (Occupational Safety and Health Administration) (1999) menyebutkan bahwa CTDs (Cumulative Trauma Disorders) adalah kelainan yang terjadi pada otot skeletal (musculoskeletal) dan system syaraf yang disebabkan oleh adanya gerakan yang berulang-ulang, penggunaan tenaga yang berlebihan, getaran, tekanan mekanik (permukaan yang kasar atau tajam), postur yang salah dan jangka waktu yang lama atau terus menerus, atau paparan bising yang berlebihan dalam jangka waktu lama. Jadi keluhan nyeri yang dirasakan pekerja seperti pada lengan, tangan dan pergelangan tangan dapat juga disebabkan oleh gerakan berulang dan bukan hanya karena faktor posisi kerja tidak alamiah.

Uji hipotesis kedua menunjukkan bahwa stress kerja yang dialami pekerja setelah menggunakan kursi kerja ergonomis menurun $16.24 \%$. Penurunan tersebut antara lain karena pengggunaan kursi kerja yang mempunyai sandaran punggung, sandaran tangan, penggunaan topangan kaki yang tepat sehingga memberi kenyamanan. Jadi senada dengan Setyawati (2000) pekerja pembatik tulis dengan tempat duduk ergonomis berdampak adanya penurunan stress kerja pada subyek dan senada dengan Kusuma (2004) bahwa semakin rendah stress kerja akan menimbulkan peningkatan prestasi kerja.

\section{Kesimpulan :}

\section{Kesimpulan dan Saran}

1. Penggunaan kursi kerja yang ergonomis menurunkan keluhan nyeri pada pekerja bagian pijar perusahaan lampu PT. X

2. Penggunaan kursi kerja yang ergonomis menurunkan stress kerja yang dialami oleh pekerja bagian pijar perusahaan lampu PT. X

Saran :

Perlunya pengawasan berkelanjutan dan penyuluhan tentang tentang cara penggunaan kursi yang tepat dengan posisi kerja yang benar disamping mengembalikan kursi setelah istirahat dan kembali bekerja dengan mengatur penempatan posisi kursi yang benar sebelum dipergunakan untuk bekerja kembali.

\section{DaftarPustaka}

[1] Clark. D.R, 1996. Workstation Evaluation and Design, Bhattacharya, A, and McGlothlin. J.D., Occupational Ergonomics: Theory and Application. New York. 279-327

[2] Corlet, E.N., 1992. Static Muscl Loading and the Evaluation of Posture, Wilson J.R. \& Corlett H.N., Evaluation of Human Work a Practice! Ergonomics Methodology, Tailor \& Francis. London.

[3] Grandjean, E., 1993. Fitting the Task to the Man, a Texbook of Occupational Ergonomics, $4^{\text {th }}$ ed. Taylor \& Francis, London.

[4] Harrington, J.M., \& Gill, F.S., 1983. Occupational Health, Blackwell Scientific Publications, London. 
[5] Levy, B.S., and Wegman, D.H., 1988. Occupational Health. $2^{\text {nd }}$ ed., Little Brown \& Company. Boston / Toronto.

[6] Manuaba, A., 2000. Ergonomi, Kesehatan dan Keselamatan Kerja, Sritomo Wignyosoebroto dan Wiranto. Stefanus E., 2000. Proceeding Seminar Nasional Ergonomi 2000. Gunawijaya. Surabaya 1-4

[7] Pratiknya, A.W., 2001. Dasar-dasar Metodologi Penelitian Kedokteran dan Kesehatan. Rajawali, Jakarta.

[8] Puja, I.B.P., 2000. Perbaikan Sikap Kerja Duduk Mengurangi Gangguan Sistem Musculoskeletal dan Meningkatkan Produktivitas Kerja Perajin Batok Kelapa di Desa Koripan, Kecamatan Banjarangkan Kabupaten Klungkung. Tesis, Tidak Dipublikasikan, Program Studi Ergonomi Fisiologi Kerja Program Pascasarjana, Universitas Udayana, Bali.

[9] Purnawan, I.B., 2000. Perbaikan Sikap Kerja Mengurangi Keluhan Subyektif Perajin Layang-layang Home Industry Sanur, Bali, Proceeding Seminar Nasional Ergonomi 2000. Guna Widya, Surabaya.

[10] Setyawati, L., 2000. Ergonomi, Kumpulan Makalah Hiperkes, Volume I, Periode 1995 s/d 1997. Yogyakarta. $45-56$

[11] Waters, T.S. \& Putz-Anderson, V. 1996. Revise NIOSH Liffing Equation, Bhattacharya, A., and McGlothlin, J.D., Occupational Ergonomics: Theory and Application. New York. 627-654 